\title{
A representação social do profissional analista de sistemas da informação: relato de pesquisa
}

Maria Heldaiva Bezerra Pinheiro ${ }^{1}$

Resumo - Com base na definição de representação social como forma de conhecimento prático, foi realizada uma pesquisa a fim de analisar o fenômeno da imagem do profissional analista de sistemas da informação e suas representações. Buscou-se identificar como ele vê seu relacionamento com o usuário/cliente, seu entendimento sobre a competência profissional, as competências essenciais para sua área de atuação e sua reputação. Este artigo demonstra o resultado dessa pesquisa.

Palavras-chave: profissional da informação; representação social; competência profissional.

Abstract - Based social representation knowledge definition, a survey was conducted to analyze the professional image analyst phenomenon, information systems and their representations. It was tried to identify how they see his client/user relationship, and their professional competence understanding, essential skills to their expertise area and reputation. Research results are showed.

Keywords: information data processing professionals; social representation; professional competence.

\footnotetext{
${ }^{1}$ Aluna especial do Programa de Pós-Graduação em Ciência da Informação - PPGCInf da Faculdade de Ciência da Informação - UNB-DF.
} 


\section{Introdução}

Este trabalho parte da premissa de que a incorporação de novas tecnologias ao processo de gestão é condição essencial ao desenvolvimento das organizações modernas e que o analista de sistemas, um dos profissionais da área de Tecnologia da Informação - TI, exerce um papel preponderante nessa incorporação. As atividades atribuídas ao analista de sistemas e à profissão ligada à análise de sistemas são extremamente amplas e essenciais para a organização. Considerando-se a rápida evolução da $\mathrm{TI}$, é fundamental uma constante atualização desse profissional que precisa possuir capacitação em campos diferentes e conhecer administração de empresas, além de ter habilidade no relacionamento com pessoas, pois, frequentemente, deverá interagir com os usuários, co-participantes no desenvolvimento dos sistemas. Daí a importância da compreensão dos fatores que compõem a representação do analista de TI na sociedade globalizada e na sociedade da informação. Levy $(1999$, p. 118) reconhece a importância da constante atualização do profissional quando diz:

Pela primeira vez na história da humanidade, a maioria das competências adquiridas por uma pessoa no começo de seu percurso profissional serão obsoletas no fim de sua carreira. A segunda constatação, fortemente ligada à primeira, concerne à nova natureza do trabalho, na qual a parte de transação de conhecimentos não pára de crescer. Trabalhar equivale cada vez mais a aprender, transmitir saberes e produzir conhecimentos.

O interesse pelo estudo da representação social do analista de sistemas surgiu a partir do estudo da pesquisa realizada por Walter e Baptista (2008) sobre representações profissionais de bibliotecários no Brasil. Com base nesse trabalho, foi feita uma pesquisa com analistas de sistemas a fim de compreender o fenômeno de sua imagem profissional e suas representações sociais sob a perspectiva de Moscovici (2003).

Para Moscovici (2003), uma das funções das representações sociais é a ampliação do conhecimento da realidade por meio da inter-relação e do intercâmbio de comunicação entre o saber científico e o saber prático do senso comum, entre o 
conhecimento e a subjetividade, ou seja, é a transformação das ideias em senso comum. Essa transformação pode provocar novo significado da realidade, contradições e diferenciações e oposição entre diferentes modos de pensar.

Nesse contexto objetivou-se identificar as representações sociais que permeiam o imaginário social dos analistas de sistemas e investigar por meio do estudo como se formam e se mantêm as impressões sobre esse profissional.

Segundo Alves-Mazzotti (2008),

[...] tais representações devem ser entendidas a partir do seu processo de produção, pois investigam justamente como se formam e como funcionam os sistemas de referência que utilizamos para classificar pessoas e grupos e para interpretar os acontecimentos da realidade cotidiana.

Os dados foram coletados por meio da aplicação de questionários compostos por questões fechadas e abertas com o objetivo de identificar a representação social do analista e, com a narrativa, entender melhor o que pensam de sua profissão. A entrevista foi baseada nas diretrizes de Jovchelovitch e Bauer (2002). Segundo esses autores, a narrativa encoraja os entrevistados a relatar seus pensamentos e opiniões sobre o tema da pesquisa.

\section{As representações sociais como forma de conhecimento}

Em 1961, Moscovici (2003, p. 311) "viu a transformação do conhecimento científico em conhecimento comum como uma área de estudo possível e excitante", o que deu início à teoria das representações sociais por meio de sua obra $L a$ psychanalyse: son image et son public, revisada em 1976. Essa teoria está relacionada com o estudo das simbologias sociais e das trocas desenvolvidas nas relações interpessoais. Assim, tenta explicar o fenômeno do homem com base em uma perspectiva coletiva sem, contudo, perder de vista a individualidade.

A teoria de Moscovici está relacionada com o universo simbólico composto por ditos populares, mitologia, religião, pensamento teológico e outras tradições metafísicas e sistemas de valores e como tudo isso influencia nossa cultura na 
construção do conhecimento compartilhado. Para Moscovici (2003, p. 40), "todas as interações humanas, surjam elas entre duas pessoas ou entre dois grupos, pressupõem representações".

Em síntese, Moscovici (apud OLIVEIRA Oliveira, 2004) preocupou-se em compreender como o tripé grupos/atos/ideias constitui e transforma a sociedade. De acordo com Oliveira (2004), em resenha sobre a obra de Moscovici para a Revista Brasileira de Ciências Sociais,

"é em função das representações, e não necessariamente das realidades, que se movem indivíduos e coletividades. Saber como se formam ou como operam essas representações - onde se misturam a um só tempo pensamento primitivo, senso comum e ciência - tece a trama da obra de Moscovici".

Segundo Moscovici (2003, p. 210), "do ponto de vista dinâmico, as representações sociais se apresentam como uma 'rede' de ideias, metáforas e imagens, mais ou menos interligadas livremente e, por isso, mais móveis e fluidas que teorias".

Moscovici (1978, p. 65) defende ainda que o que as pessoas fazem e o papel que exercem nos processos sociais e na divisão do trabalho constituem uma parte mais relevante do conhecimento na sociedade do que o próprio conhecimento teórico, que é apenas uma pequena parte e de forma alguma a mais importante.

As interações sociais criam "universos consensuais" no âmbito dos quais novas representações surgem e são comunicadas:

As representações, obviamente, não são criadas por um indivíduo isoladamente. Uma vez criadas, contudo, elas adquirem uma vida própria, circulam, se encontram, se atraem e se repelem e dão oportunidade a nascimento de novas representações, enquanto velhas representações morrem (MOSCOVICl, 2003, p. 41).

Em seu artigo "O conceito de representação social na abordagem psicossocial", Spink (1993) apresenta definição clássica de Jodelet (1985) sobre as representações sociais:

São modalidades de conhecimento prático orientadas para a comunicação e para a compreensão do contexto social, material e ideativo em que vivemos. São, consequentemente, formas de conhecimento que se manifestam como elementos cognitivos imagens, conceitos, categorias, teorias -, mas que não se reduzem 
jamais aos componentes cognitivos. Sendo socialmente elaboradas e compartilhadas, contribuem para a construção de uma realidade comum, que possibilita a comunicação. Deste modo, as representações são, essencialmente, fenômenos sociais que, mesmo acessados a partir do seu conteúdo cognitivo, têm de ser entendidos a partir do seu contexto de produção. Ou seja, a partir das funções simbólicas e ideológicas a que servem e das formas de comunicação onde circulam.

O objetivo principal dessa pesquisa foi verificar a representação social do profissional da informação - especificamente dos analistas de sistemas -, analisando, do seu ponto de vista, a percepção que este tem de sua imagem e se essa é condizente com aquela vista pelos usuários dos sistemas por ele desenvolvidos, bem como sua relação com o usuário, as competências necessárias para atuar em sua área e qual sua reputação.

Moscovici (2003, p. 61) descreve dois mecanismos - ancoragem e objetivação que geram representações sociais:

O primeiro mecanismo tenta ancorar idéias estranhas, reduzi-las a categorias e a imagens comuns, colocá-las em um contexto familiar. O objetivo do segundo mecanismo é objetivá-los, isto é, transformar algo abstrato em algo quase concreto, transferir o que está na mente em algo que exista no mundo físico.

Para Alves-Mazzotti et al. (2007), a objetivação é a transferência de conceitos ou idéias em esquemas ou imagens concretas, e a ancoragem é a constituição de uma rede de significações em torno do objeto, relacionando-o a valores e a práticas sociais. Dessa forma, a representação social é criada por esses dois processos que atuam no sentido de tornar o não familiar em familiar. Assim, acredita-se que o estudo das representações sociais pode ser uma opção de análise da representação do analista, uma vez que, segundo Alves-Mazzotti (1994), investiga justamente como se formam e como funcionam os sistemas de referência utilizados, não só para classificar pessoas, grupos, circunstâncias, fenômenos e atividades, como também para interpretar os acontecimentos da realidade cotidiana, podendo recorrer aos sistemas de significação socialmente enraizados e partilhados. 


\subsection{O profissional da informação: analista de sistemas}

De acordo com a Redação Brasil Profissões, o analista de sistemas, atualmente mais conhecido como sistematizador de informações, é aquele que tem como finalidade realizar estudos de processos computacionais para encontrar o melhor e mais racional caminho para que a informação virtual possa ser processada.

Esse profissional estuda a organização procurando identificar os problemas relacionados ao fluxo de informação que possam ser resolvidos de forma mais racional; analisa e faz o levantamento das rotinas de serviços e dos fluxos de trabalho da empresa, bem como as informações para o desenvolvimento ou a alteração do sistema de processamento de dados; estuda os sistemas já existentes e o usuário final; resume as novas tecnologias de informação mais pertinentes à empresa; responsabiliza-se pela documentação dos sistemas, nos quais reúne e organiza todo o material utilizado no desenvolvimento do sistema a fim de facilitar o entendimento das funções e das futuras manutenções, evoluções ou alterações.

Enfim, o analista planeja e organiza o processamento, o armazenamento, a recuperação e a disponibilidade das informações e ainda a gestão dos projetos nos quais faz o levantamento dos requisitos, a análise, a especificação, o projeto do sistema, a programação, os testes, a homologação, a implantação e o acompanhamento dos sistemas solicitados por seus usuários.

Segundo Masiero (1999), do Instituto de Ciências Matemáticas e de Computação da Universidade de São Paulo:

O desenvolvimento do software tem um processo genérico que se divide em fases: análise do sistema, projeto, desenvolvimento e implantação. Até a década de 70 o desenvolvimento era de responsabilidade dos programadores, e a análise e projeto, considerados mais nobres e como profissão de nível superior, era de responsabilidade do analista de sistemas. Desde o início da década de 80 essa distinção diminuiu e muitos analistas de sistemas são responsáveis por todas as fases do processo. Dessa forma o nome da profissão, analista de sistemas, deriva apenas de uma das fases do processo de desenvolvimento de software, que é importante, porém não mais que as demais, e o nome do curso, Análise de Sistemas, 
reflete a profissão de um modo limitado. Esses nomes são baseados no processo. Analista de sistemas é o termo usado nos Estados Unidos e em outros países da América do Sul. De acordo com o professor, o termo "informata" seria o melhor por ser uma denominação genérica.

\subsubsection{As características necessárias do analista de sistemas}

O site Brasil Profissões define como características necessárias para o profissional que deseja ter sucesso na área: possuir raciocínio lógico, iniciativa na resolução de problemas e no desenvolvimento de softwares. Além disso, deve estar sempre pronto a mudanças e permanentemente buscando aperfeiçoamento. Necessita ainda ter várias habilidades e competências específicas, tais como:

Conhecimento do negócio: o analista deve compreender a organização funcional, os clientes e as necessidades de informação a fim de propor soluções que permitam à empresa alcançar suas metas.

Gerenciamento de projetos: é uma competência fundamental ao analista, pois o desenvolvimento de um sistema é complexo e a aplicabilidade do conhecimento em gerenciamento de projetos é fundamental para que o custo e o escopo fiquem adequados e o tempo acordado seja cumprido.

Criatividade: o profissional deve estar atento a sugestões de novas propostas para a empresa melhorar seu desempenho por meio do uso racional e criativo da tecnologia da informação.

Atualização tecnológica: o profissional deve manter-se atualizado, uma vez que a informática e a tecnologia da informação têm evoluído de forma vertiginosa nos últimos anos. O estudo, a pesquisa e o desenvolvimento tecnológico são atividades do dia a dia desse profissional.

Boas relações interpessoais: o tipo de atividade desenvolvida pelo analista necessita que haja perfeita interação e integração com os usuários, exigindo do profissional a capacidade de sentir de forma mais abrangente os problemas, as reais necessidades e as aspirações dos seus "clientes" ou interlocutores. 


\subsubsection{O papel do analista de sistemas na sociedade}

O analista de sistemas tem um importante papel na sociedade globalizada, pois é um transformador nas organizações. Com a incorporação de novas tecnologias na solução dos diversos problemas de uma empresa, propicia novas atividades e melhora as condições de trabalho e de vida. Para o alcance de tão relevante papel, ele deve estar constantemente atualizado e ter o domínio das novas tecnologias da informação e da gestão da área de sistemas.

\subsubsection{A formação necessária para ser analista de sistemas}

Com o surgimento de novos cursos mais específicos que preparam melhor o profissional para o exercício da profissão, o curso Análise de Sistemas - bacharelado, com duração de quatro anos - está sendo aos poucos substituído pelos cursos: Sistema de Informação, Ciência da Computação, Ciência da Informação, entre outros, todos eles com duração média de quatro anos e com forte inter-relação.

Para exercer a função de analista de sistema o profissional deve estar sempre atualizado para acompanhar o rápido progresso da tecnologia. Bons conhecimentos em inglês são indispensáveis.

\subsection{4 Áreas de atuação e mercado de trabalho}

Existe uma gama de atividades em que um analista de sistemas pode atuar: análise de sistemas; auditoria de sistemas de informação; projeto e engenharia de software; administração de banco de dados; gerência de área; gerência/administração de redes de pequeno e médio portes; docência no ensino de informática.

Com a explosão da tecnologia e a tendência à informatização generalizada nos diversos setores da empresa e também pela constante necessidade de modernização e competitividade no mercado, o campo de trabalho para os profissionais da área de informática - Sistemas de Informação, Ciência da Computação, Análise de Sistemas encontra-se aquecido e em pleno desenvolvimento tanto no setor público quanto no privado. 


\section{A pesquisa com os analistas de sistemas e usuários -resultados}

A pesquisa foi realizada por meio de questionário com perguntas abertas e fechadas. Optou-se por perguntas abertas como forma de encorajar os entrevistados a relatar suas opiniões sobre o tema da pesquisa.

O questionário foi divido em dois blocos de questões direcionadas ao profissional de TI e ao usuário. Foi aplicado em uma pequena amostra de profissionais da tecnologia da informação lotados no cargo de analistas de sistemas de uma instituição pública de Ensino Superior e também com os respectivos usuários dos sistemas desenvolvidos por esses analistas. Nesse caso foram escolhidos usuários de diversas áreas. O total de respondentes foi de nove analistas de sistema e dez usuários.

A escolha dos sujeitos na instituição foi baseada em alguns critérios: analistas com menos tempo de atuação, com médio e mais tempo de atuação na profissão e com usuários das áreas dos principais sistemas - Recursos Humanos, Compras, Patrimônio e da área fim da instituição.

O instrumento para a coleta de dados tomou foi baseado nas orientações de Jovchelovitch e Bauer (2002). O questionário foi aplicado pessoalmente, com hora previamente marcada, e posteriormente transcrito para o google docs.

\section{Resultados e discussões}

As perguntas abertas foram analisadas e compiladas a fim de demonstrar de forma geral as opiniões dos entrevistados. A seguir são apresentados a tabulação e os gráficos demonstrativos. 


\subsection{Profissionais de TI}

\subsubsection{Seu curso superior foi concluído em que tipo de faculdade?}

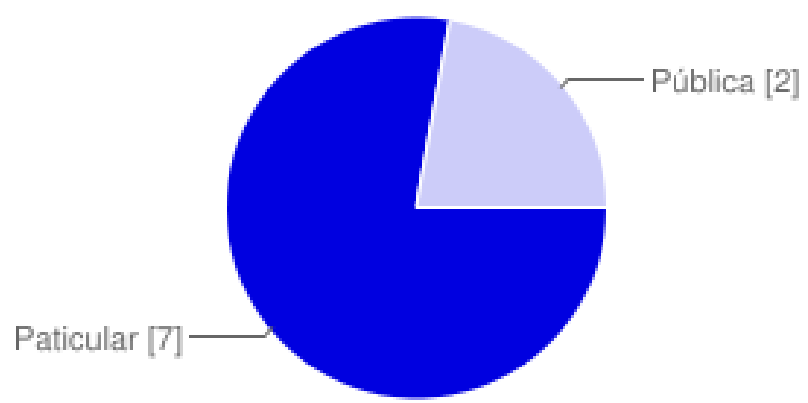

Particular 7 78\%

Pública $222 \%$

Gráfico 1

Fonte: elaboração da autora

\subsubsection{Há quanto tempo você concluiu seu curso superior?}

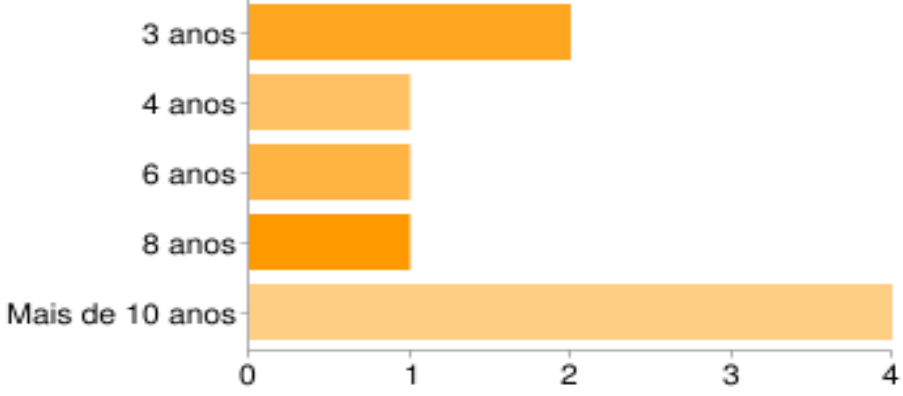

$\begin{array}{lll}3 \text { anos } & 2 & 22 \% \\ 4 \text { anos } & 1 & 11 \% \\ 6 \text { anos } & 1 & 11 \% \\ 8 \text { anos } & 1 & 11 \% \\ \text { Mais de } 10 \text { anos } & 4 & 44 \%\end{array}$

Gráfico 2

Fonte: elaboração da autora 


\subsubsection{Quais os cursos realizados além da graduação?}

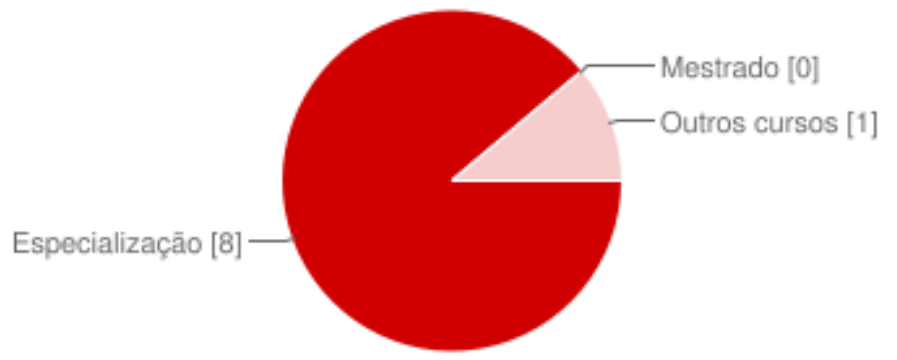

$\begin{array}{lcr}\text { Especialização } & 8 & 89 \% \\ \text { Mestrado } & 0 & 0 \% \\ \text { Outros cursos } & 1 & 11 \%\end{array}$

Gráfico 3

Fonte: elaboração da autora

\subsubsection{Possui outra graduação?}

$\begin{array}{lllr} & \operatorname{Sim} & 0 & 0 \% \\ & \text { Não } & 9 & 100 \% \\ \text { Não [9]- } & & & \\ -\operatorname{Sim}[0] & & & \end{array}$

Gráfico 4

Fonte: elaboração da autora 


\subsubsection{Os cursos que participou, relacionados à sua área de atuação ocorreram:}

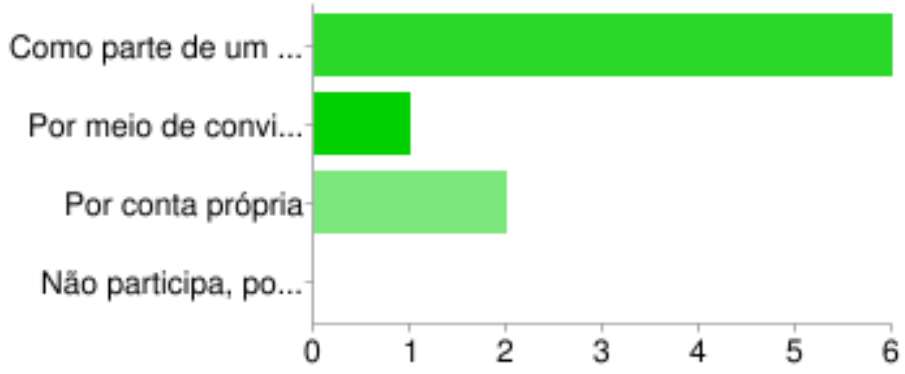

Como parte de um programa de treinamento oferecido

$6 \quad 67 \%$ pela empresa

Por meio de convites e patrocínio

$111 \%$

Por conta própria

$222 \%$

Não participa, pois não vê relevância atual para a profissão

Gráfico 5

Fonte: elaboração da autora

\subsubsection{Você se sente realizado como analista de TI?}

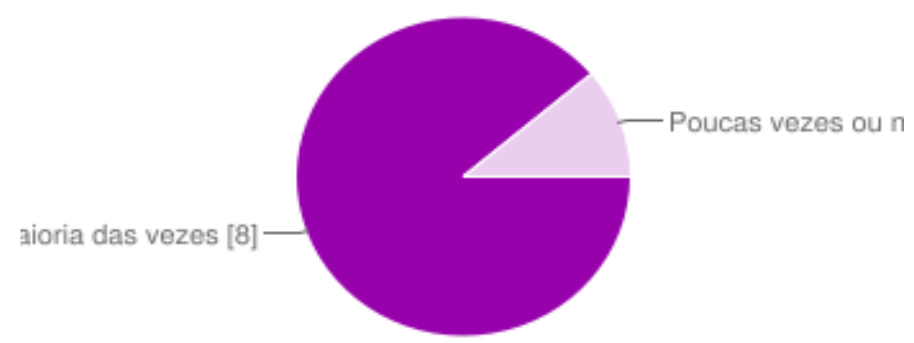

$\begin{array}{lll}\text { Sempre ou na maioria das vezes } & 8 & 89 \% \\ & 1 & 11 \%\end{array}$

Gráfico 6

Fonte: elaboração da autora 


\subsubsection{Acredita ter uma reputação positiva na área que atua?}

$\checkmark$ Sim, sou alguém que gosta do que faz e gosta de aprender; desempenho em realizar as tarefas dá uma maior credibilidade às pessoas.

$\checkmark$ Sim, normalmente tenho cumprido todos os objetivos propostos.

$\checkmark$ Sim, pois a maioria dos trabalhos entregues à minha pessoa obteve sucesso.

$\checkmark \operatorname{Sim}$, pois na área de redes qualquer mudança é facilmente notada pelo usuário final.

$\checkmark$ Acredito que tenho uma reputação positiva em relação à capacidade de solucionar problemas, desenvolver e implementar projetos de sistemas. Contudo, a reputação em relação ao cumprimento de horário não é positiva.

4.1.8 Você acha que o analista de TI com menos de cinco anos de experiência em relação a outro com mais de vinte anos é:

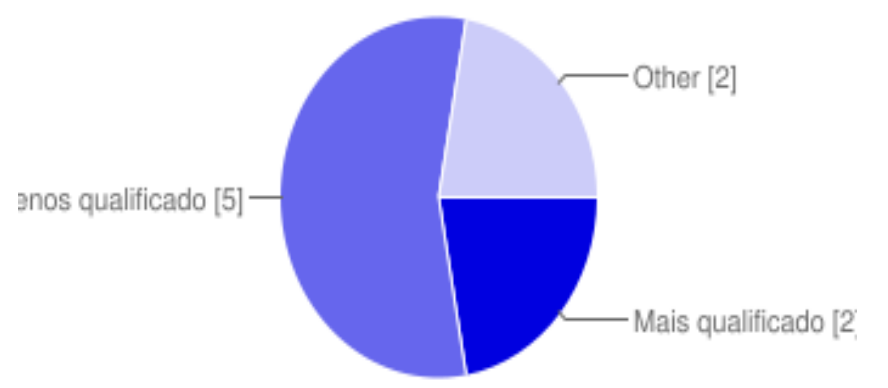

$\begin{array}{lll}\text { Mais qualificado } & \mathbf{2} & 22 \% \\ \text { Menos qualificado } & \mathbf{5} & 56 \% \\ \text { Outros } & \mathbf{2} & 22 \%\end{array}$

Gráfico 7

Fonte: elaboração da autora 


\subsubsection{Como é seu relacionamento com o usuário/cliente?}

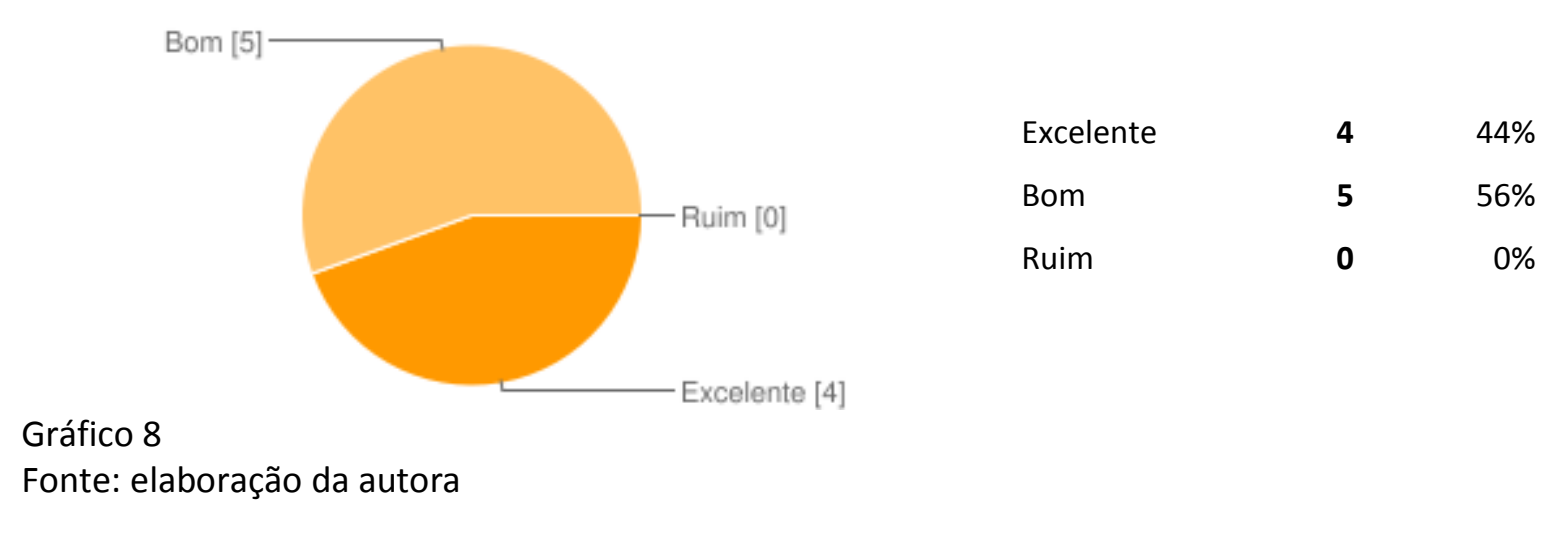

\subsubsection{O que você entende como competência profissional na sua área?}

$\checkmark$ Sendo TI uma área ampla, penso que um profissional da área deve ter muito conhecimento a respeito, deve saber muito sobre o que especificamente faz, porém tem de ter um conhecimento amplo também.

$\checkmark$ Proporcionar à organização soluções para os sistemas de informação com ajuda da tecnologia.

$\checkmark$ Busca contínua pelo conhecimento e aplicação deste na prática.

$\checkmark$ Minha área de atuação está vinculada à criação de um produto e à aceitação e ao uso deste pelo cliente.

$\checkmark$ É a soma de fatores essenciais ao bom desenvolvimento das atividades cotidianas da área.

$\checkmark$ Acredito que seja um conjunto de habilidades que um profissional deve possuir para desempenhar as funções inerentes a determinada área. 


\subsubsection{Quais as competências essenciais para atuar na sua área?}

$\checkmark$ Dinamismo, curiosidade, autoaprendizado.

$\checkmark$ Observador, pensamento abstrato, disciplina e bom relacionamento interpessoal.

$\checkmark$ Planejamento, organização e lógica.

$\checkmark$ Gerência de projetos e gestão de pessoas.

$\checkmark$ Conquistar a confiança do usuário envolvendo-o para obter sucesso na criação de um produto.

$\checkmark$ Adaptação brusca a novas rotinas, criatividade, poder de percepção, iniciativa, etc.

$\checkmark$ Conhecimento técnico - o profissional deve conhecer bem as tecnologias que serão utilizadas e possuir capacidade de utilizar com eficiência os conhecimentos técnicos na aplicação do desenvolvimento das necessidades do cliente.

\subsubsection{Você se vê como um profissional da informação?}

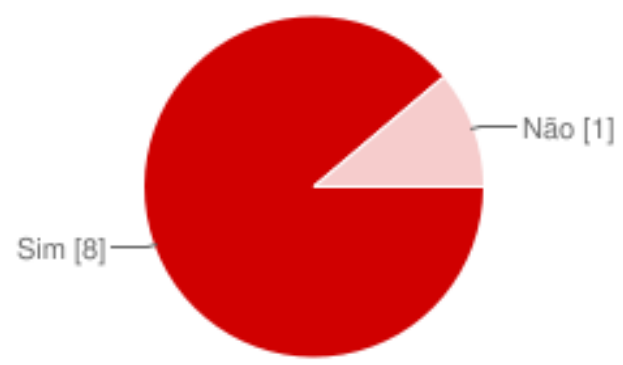

$\begin{array}{lll}\text { Sim } & \mathbf{8} & 89 \% \\ \text { Não } & \mathbf{1} & 11 \%\end{array}$

Gráfico 9

Fonte: elaboração da autora 
4.1.13 Você ouve e detecta as especificações tomando por base a opinião do usuário?

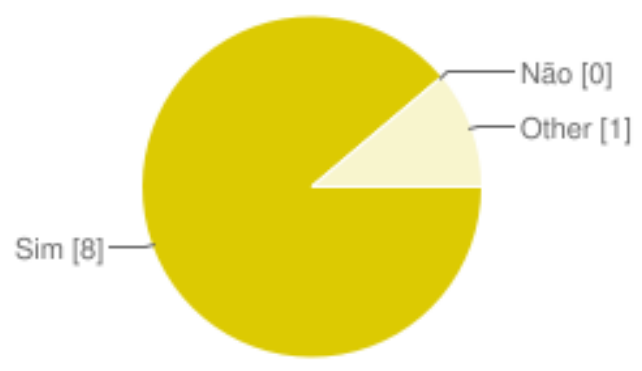

$\begin{array}{lrr}\text { Sim } & 8 & 89 \% \\ \text { Não } & 0 & 0 \% \\ \text { Outro } & 1 & 11 \%\end{array}$

Gráfico 10

Fonte: elaboração da autora

\subsubsection{Você acredita que seu salário/remuneração está para na média da profissão?}

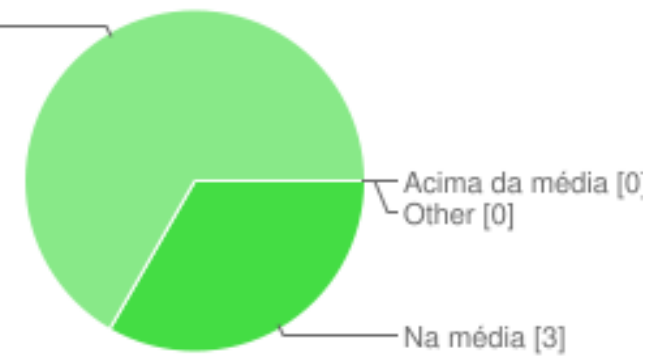

\section{Acima da média}

Na média

Abaixo da média
$0 \%$

$333 \%$

$667 \%$

Gráfico 11

Fonte: elaboração da autora

\subsubsection{Você tem alguma meta profissional?}

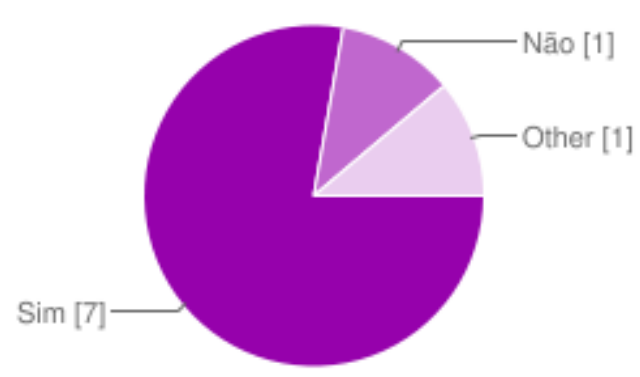

$\begin{array}{lll}\text { Sim } & 7 & 78 \% \\ \text { Não } & 1 & 11 \% \\ \text { Outra } & 1 & 11 \%\end{array}$

Gráfico 12

Fonte: elaboração da autora 
4.1.16 Em caso afirmativo, quais destas metas se aproximam de suas expectativas futuras?

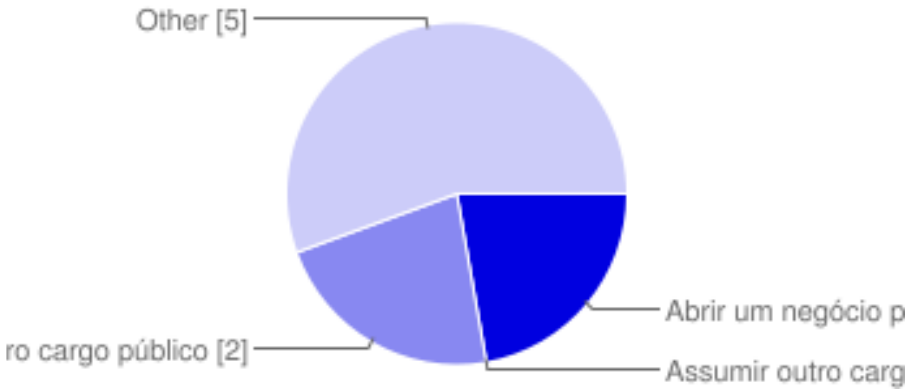

$\begin{array}{lll}\text { Abrir um negócio próprio } & 2 & 22 \% \\ \begin{array}{l}\text { Assumir outro cargo na } \\ \text { instituição }\end{array} & 0 & 0 \% \\ \begin{array}{l}\text { Buscar outro cargo } \\ \text { público }\end{array} & 2 & 22 \% \\ \begin{array}{l}\text { Outras } \\ \text { nutra }\end{array} & 5 & 56 \%\end{array}$

Gráfico 13

Fonte: elaboração da autora

$109 \quad 4.2$ Usuários

A seguir são apresentados os resultados da entrevista com os usuários dos sistemas desenvolvidos ou mantidos pelos analistas entrevistados.

\subsubsection{Como é o relacionamento com o analista de sistemas?}

Gráfico 14

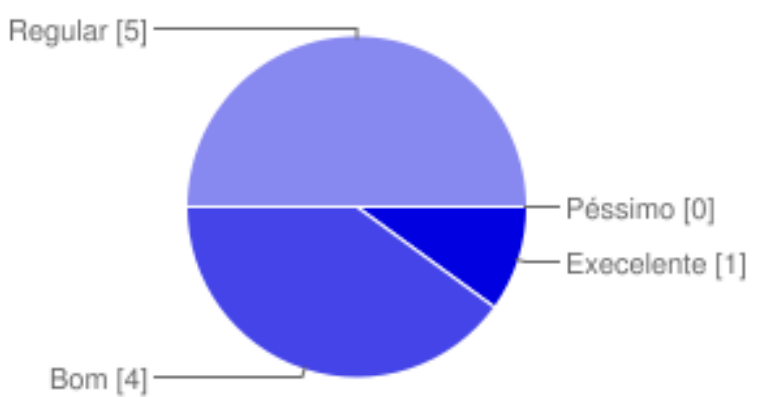

$\begin{array}{lll}\text { Excelente } & 1 & 10 \% \\ \text { Bom } & 4 & 40 \% \\ \text { Regular } & 5 & 50 \% \\ \text { Péssimo } & 0 & 0 \%\end{array}$

Fonte: elaboração da autora

RICI: R.Ibero-amer. Ci. Inf., ISSN 1983-5213, Brasília,v. 3, n. 1, p. 93-114, jan./jul. 2011. 


\subsubsection{Você sente que suas necessidades em relação ao desenvolvimento do sistema foram atendidas?}

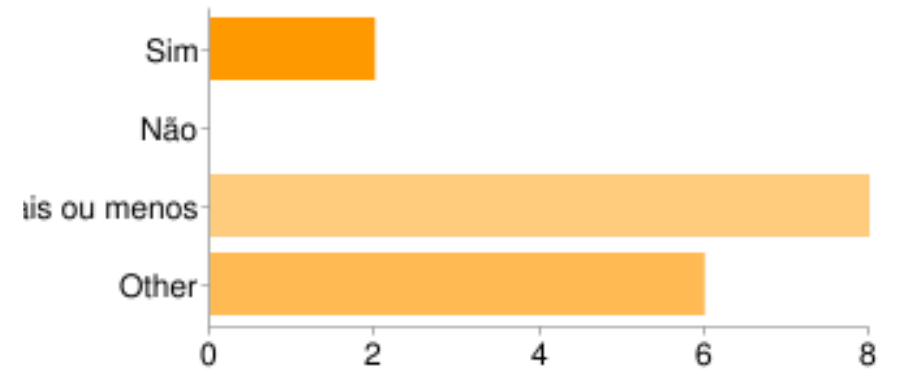

$\begin{array}{lrr}\text { Sim } & 2 & 20 \% \\ \text { Não } & 0 & 0 \% \\ \text { Mais ou menos } & 8 & 80 \% \\ \text { Outras } & 6 & 60 \%\end{array}$

Gráfico 15

Fonte: elaboração da autora

110

Obs.: era possível marcar mais de uma opção no caso de resposta negativa, por esse motivo a porcentagem ultrapassou $100 \%$.

\subsubsection{Com breves palavras, relate qual é a imagem que você tem do analista de sistemas da informação}

$\checkmark$ Há sempre boas intenções dos analistas em atender às nossas necessidades.

$\checkmark$ São profissionais de extrema competência com excelente grau de conhecimento na área.

$\checkmark$ Politicamente não conseguem avançar com os projetos. Existe, ainda, desmotivação com relação à questão financeira, baixos salários.

$\checkmark$ "Posam" que sabem tudo e não aceitam opiniões.

$\checkmark$ Acham que o usuário não sabe de nada. 
$\checkmark$ É meio difícil ter uma imagem de alguém que dificilmente é encontrado no trabalho.

$\checkmark$ Prepotente, arrogante, sempre acha que sabe mais que o usuário.

$\checkmark$ Alheio aos outros departamentos.

$\checkmark$ São qualificados.

$\checkmark$ Falta conhecimento.

\subsection{Análise dos dados}

Ao analisar os dados obtidos no decorrer da entrevista, foram constatadas algumas inconsistências relevantes. A primeira delas refere-se à insatisfação salarial do profissional analista de sistemas e seu desejo de alcançar novas metas, embora se sinta realizado profissionalmente. Essa manifestação deve ser levada em consideração pela instituição pesquisada, uma vez que a perda de um profissional treinado gera um alto custo tanto pelo investimento feito no profissional que sai da empresa como em razão do investimento a ser aplicado nos novos profissionais contratados.

Os dados apresentados demonstraram que todos os analistas entrevistados possuem curso superior e que embora $89 \%$ deles tenham feito uma especialização não cursaram mestrado. Considerando que profissionais de outra formação podem estar ocupando um cargo de analista de sistemas, após a conclusão da pesquisa verificou-se que este seria um dado importante a ser averiguado, o que dever ser feito em estudo posterior. Além disso, percebeu-se ser necessária a averiguação do gênero, pois na instituição pesquisada a maioria dos analistas é do sexo masculino, sendo importante verificar se esta é uma característica da profissão.

Com relação à atualização profissional, verificou-se que esta vem sendo realizada, normalmente, por iniciativa da instituição, há pouco investimento próprio na especialização.

Constatou-se que a auto-estima desse profissional é excelente, pois $89 \%$ dos entrevistados sentem-se realizados na profissão. 
A instituição pesquisada tem metade do seu quadro de analista com menos de cinco anos de casa e a outra metade com mais de vinte anos. Com essa constatação, buscouse verificar se na opinião dos respondentes a qualificação do profissional está relacionada ao tempo de serviço. Dos entrevistados, 56\% acham que sim, porém $22 \%$ entendem que os analistas com menos de cinco anos são mais qualificados e estão mais preocupados com o quesito "atualização profissional". O curioso é que os mais novos de casa responderam que os mais antigos são mais qualificados. Em contrapartida, os mais antigos acreditam que os mais jovens estão mais bem preparados.

Quanto ao relacionamento do usuário com o analista de sistemas, há uma grande divergência entre as respostas de ambos, pois a metade dos usuários acha o relacionamento entre eles regular, $40 \%$ bom e apenas $10 \%$ acham excelentes. Contudo, $50 \%$ dos analistas pesquisados avaliam como bom e 50\% consideram excelente seu relacionamento com os usuários.

Para a maioria dos usuários entrevistados, a imagem do analista de sistemas é 112 extremamente negativa, pois sua necessidade em relação ao desenvolvimento do sistema não está sendo satisfatoriamente atendida. Esse dado demonstra a insatisfação do usuário e uma considerável divergência entre as opiniões de ambos quanto à imagem do analista de sistemas. Dessa forma, conclui-se pela necessidade do aprofundamento do estudo, considerando as contradições entre as avaliações. Apesar disso, os profissionais entrevistados consideram ter uma reputação positiva na área em que atuam.

Quanto ao salário/remuneração, a maioria dos entrevistados considerou seu salário abaixo da média do mercado, o que gera insatisfação. Este é um importante dado de gestão para a instituição pesquisada, uma vez que esse tipo de profissional é muito bem remunerado no mercado, levando a instituição a correr o risco de perder seus melhores profissionais. Constatou-se que este fator é um dos motivos da grande rotatividade de profissionais da área.

A maioria dos entrevistados manifestou interesse em atingir outras metas profissionais, embora $56 \%$ não saibam que metas são essas, e $22 \%$ deles desejam abrir 
um negócio próprio. Infere-se que a questão salarial influencia nesta decisão. A instituição pesquisada é pública e não tem poder para alterar a situação.

Quanto às competências essenciais para sua área de atuação, a maioria dos respondentes demonstrou não ter conhecimento pleno de quais seriam essas competências.

Embora 50\% dos entrevistados tenham apontado para a necessidade da busca contínua pelo conhecimento e atualização tecnológica como competências essenciais para atuar na área, a maioria deles recebe treinamento oferecido pela própria empresa, apenas $30 \%$ investiu na sua capacitação.

\section{Conclusão e trabalhos futuros}

O desenvolvimento que se verifica hoje na área de tecnologia da informação está, sem dúvida, estimulando as mudanças que ocorrem no nosso dia a dia. Aprender a viver em um fluxo constante com eventos e mudanças é algo necessário. $\mathrm{O}$ analista

113 de sistemas exerce um papel importante nessas mudanças.

Pela pesquisa, verificou-se existir um conflito de opiniões entre os profissionais e seus clientes, os usuários. Dessa forma sugere-se a continuidade da pesquisa, estendendo-a a outras instituições públicas e privadas a fim de verificar se o fenômeno se repete, investigar com maiores detalhes o perfil do profissional analista de sistemas e por fim explorar as relações entre as mudanças na sociedade e o desenvolvimento dos sistemas de softwares.

É necessário ressaltar que uma vez que este estudo contemplou apenas os profissionais e os usuários de uma instituição pública, não convém generalizar o conflito apresentado, devendo nova pesquisa ser realizada abordando profissionais tanto de instituições públicas quanto privadas.

Finalmente, entende-se ser importante o aprofundamento da pesquisa a fim de verificar como as representações sociais são criadas e o que faz com que elas permaneçam existindo. 


\section{Referências}

ALVES-MAZZOTTI, A. J. Representações sociais: aspectos teóricos e aplicações à educação. Em Aberto, Brasília, v. 61, n. 61, p. 60-78, 1994.

. Representações sociais: aspectos teóricos e aplicações à educação. Revista

Múltiplas Leituras, v. 1, n. 1, p. 18-43, 2008.

JODELET, D. La representación social: fenómenos, concepto y teoría. In: MOSCOVICI, S. (Org.). Psicologia social. Barcelona: Paidós, 1985. p. 469-494.

JOVCHELOVITCH, Sandra; BAUER, Martin. Entrevista narrativa. In: BAUER, Martin W.; GASKELL, George (Org.). Pesquisa qualitativa com texto, imagem e som: um manual prático. Petrópolis: Vozes, 2002.

LÉVY, P. The universal without totality: the essence of cyberculture. In: LARRETA, E. R. (Org.). Media and social perception. Rio de Janeiro: Unesco, ISSC, Educam, 1999. p. 191-208.

MASIERO, C. Paulo. Sistemas de informação ou análise de sistemas? São Paulo: USP, 1999. Disponível em: <http://www.icmc.sc.usp.br/ masiero/nomesist.htm> Acesso em: 20/01/2011.

MOSCOVICI, S. A representação social da psicanálise. Rio de Janeiro: Zahar, 1978.

Representações sociais: investigações em psicologia social. Rio de Janeiro:

Vozes, 2003.

OLIVEIRA, Márcio S. B. S. Rev. Bras. Ci. Soc., São Paulo, v.19, n. 55, jun. 2004. Disponível em: <http://www.scielo.br/scielo.php>. Acesso em: 15/01/2011.

Brasil profissões. Disponível

em:<http://www.brasilprofissoes.com.br/profissoes/analista-de-sistemas $>$. Acesso em: 15/01/2011.

SPINK, Mary Jane P. The concept of social representations in social psychology. Cad. Saúde Pública, Rio de Janeiro, v. 9, n. 3, p. 300-308, jul./set. 1993. Disponível em: <http://www.scielosp.org/pdf/csp/v9n3/17>. Acesso em: 03/01/2011.

WALTER, Maria Tereza Machado T. ; BAPTISTA, Sofia Galvão. Representações profissionais de bibliotecários no Brasil: alguns resultados de pesquisa. Encontros Bibli, , v. 14, n.27, 2009. 